\title{
Different electrophysiological effects of the levo- and dextrorotatory isomers of mexiletine in isolated rabbit cardiac muscle
}

\begin{tabular}{|r|l|}
\hline Journal: & Canadian Journal of Physiology and Pharmacology \\
\hline Manuscript ID & cjpp-2016-0599 \\
\hline Manuscript Type: & Article \\
\hline Date Submitted by the Author: & $24-$ Oct-2016 \\
\hline Complete List of Authors: & $\begin{array}{l}\text { Gurabi, Zsolt ; Szegedi Tudomanyegyetem, Department of Pharmacology } \\
\text { and Pharmacotherapy } \\
\text { Patocskai, Bence ; Medical Faculty Mannheim, University of Heidelberg, } \\
\text { First Department of Medicine } \\
\text { Györe, Balázs; University of Szeged } \\
\text { Virág, László; University of Szeged, Department of Pharmacology and } \\
\text { Pharmacotherapy; HUngarian Academy of Sciences, Division of } \\
\text { Cardiovascular Pharmacology } \\
\text { Mátyus, Péter; Semmelweis Egyetem } \\
\text { Papp, Julius; Universiy of Szeged,, Department of Pharmacology and } \\
\text { Pharmacotherapy } \\
\text { Varró, András; University Szeged, Department of Pharmacology and } \\
\text { Pharmacotherapy } \\
\text { Koncz, Istvan; Szegedi Tudomanyegyetem, Department of Pharmacology } \\
\text { and Pharmacotherapy }\end{array}$ \\
\hline \multirow{2}{*}{ Keyword: } & $\begin{array}{l}\text { R-(-) mexiletine, S-(+) mexiletine, papillary muscles, Vmax, conduction } \\
\text { time, early extrasystoles }\end{array}$ \\
\hline
\end{tabular}




\section{Different electrophysiological effects of the levo- and dextrorotatory isomers of mexiletine in isolated rabbit cardiac muscle}

Zsolt Gurabi ${ }^{\mathrm{a}}$, Bence Patocskai ${ }^{\mathrm{a}, \mathrm{b}, \mathrm{f}}$, Balázs Györe ${ }^{\mathrm{c}}$, László Virág ${ }^{\mathrm{a}}$, Péter Mátyus ${ }^{\mathrm{d}}$, Julius Gy. Papp $^{\mathrm{a}, \mathrm{e}}$, András Varró ${ }^{\mathrm{a}, \mathrm{e}}$, István Koncz ${ }^{\mathrm{a}}$

${ }^{\mathrm{a} D e p a r t m e n t ~ o f ~ P h a r m a c o l o g y ~ \& ~ P h a r m a c o t h e r a p y, ~ F a c u l t y ~ o f ~ M e d i c i n e, ~ U n i v e r s i t y ~ o f ~}$ Szeged, Szeged, Hungary;

${ }^{b}$ First Department of Medicine, Medical Faculty Mannheim, University of Heidelberg, Mannheim, Germany

${ }^{c}$ Faculty of Dentistry, University of Szeged, Hungary

${ }^{\mathrm{d}}$ Department of Organic Chemistry, Faculty of Pharmacology, Semmelweis University, Budapest, Hungary

${ }^{\mathrm{e}}$ Hungarian Academy of Sciences - University of Szeged (MTA-SZTE) Research Group of Cardiovascular Pharmacology, Szeged, Hungary

${ }^{\mathrm{f}}$ DZHK (German Center for Cardiovascular Research), Partner Site Heidelberg-Mannheim, Germany

\footnotetext{
*Author for correspondence at:

András Varró MD, DSc

Department of Pharmacology \& Pharmacotherapy

Faculty of Medicine

University of Szeged

Dóm tér 12,

H-6721 Szeged, Hungary

Telephone: +3662545683

Fax: +36-62-545680

E-mail: varro.andras@med.u-szeged.hu
} 


\section{ABSTRACT}

Racemic mexiletine is a widely used antiarrhythmic agent which blocks sodium channels. The effects of R-(-) and S-(+) mexiletine stereoisomers on maximum rate of depolarization (Vmax), conduction time and repolarization have not yet been investigated in isolated cardiac preparations. We studied the effect of the R-(-) and S-(+) mexiletine on rabbit cardiac action potential parameters by using the conventional microelectrode technique. Both enantiomers at $20 \mu \mathrm{M}$ of therapeutically and experimentally relevant concentration, significantly depressed the Vmax at fast heart rates (BCLs $300-700 \mathrm{~ms}$ ). R-(-) mexiletine has more potent inhibitory effect than S-(+) mexiletine. Both R-(-) and S-(+) mexiletine significantly inhibited the Vmax of early extrasystoles measured at $70 \mathrm{~ms}$ diastolic interval induced by S1-S2 stimuli. R-(-) mexiletine has more pronounced inhibitory effect than S-(+) mexiletine. Both R-(-) and S-(+) mexiletine increased significantly the ERP/APD 90 ratio. The time constant $(\tau)$ of recovery of Vmax was found to be $\tau=376.0 \pm 77.8 \mathrm{~ms}$ for R-(-) mexiletine and $\tau=227.1 \pm 23.4 \mathrm{~ms}$ for S(+) mexiletine which indicates a slower offset kinetics for R-(-) mexiletine from sodium channels than that of the S-(+) enantiomer. These data suggest that R-(-) mexiletine might be more potent antiarrhythmic agent than S-(+) mexiletine.

Keywords: R-(-) mexiletine, S-(+) mexiletine, papillary muscles, Vmax, conduction time, early extrasystoles 


\section{Introduction}

The compound Kö 1173, later denominated mexiletine, exerted anticonvulsant activity in animal experiments. Since 1972 mexiletine has been recognized as an antiarrhythmic agent with characteristics similar to those of lidocaine (Vaughan Williams 1998). The racemic mexiletine had been classified as a Class $1 \mathrm{~b}$ antiarrhythmic compound (Vaughan Williams 1998), which blocks sodium channels in a use dependent manner with relatively fast onset and offset kinetics of Vmax block (Campbell 1983; Varró et al. 1985). The most important advantage of mexiletine over lidocaine is its good oral availability and longer half-life. Mexiletine reduces use-dependently the magnitude of fast sodium current (Hering et al. 1983), markedly slows premature conduction (Hohnloser et al. 1982), suppresses abnormal automacity in Purkinje fibers (Sarkozy and Dorian 2007) and shortens the durations of action potentials (Arita et al. 1979; Yamaguchi et al. 1979). The main cardiac indication of mexiletine is the treatment of ventricular arrhythmias (Mason 1993; Singh et al. 1990). At present, there is a need for available pharmacotherapy to target directly the ionic basis of most long QT syndromes (LQTS) for the acute termination of torsades de pointes (TdP) arrhythmia. In a recent article it has been reported that mexiletine may be an effective treatment approach to terminate refractory TdP from several acquired causes of LQTS (Badri et al. 2015). Mexiletine is applied in extracardiac disorders, too. It is widely administered in the therapy of myotonic disorders (Logigian et al. 2010; Statland et al. 2012), in Timothy syndrome (Gao Y. et al. 2013), in neuropathies (O’Connor and Dworkin 2009) and in chronic pain (Park and Moon 2010). A recent study (Weiss et al. 2016) have provided Class I evidence that mexiletine has been safe when given daily to patients with amyotrophic lateral sclerosis (ALS). Mexiletine therapy has resulted in large dose-dependent decreases in muscle cramp frequency and severity. The racemic mexiletine preparations containing both isomers (R-(-) and S-(+) mexiletine), are used therapeutically. De Luca et al. demonstrated the 
stereoselective effects of mexiletine enantiomers on sodium currents and excitability of skeletal muscle fibers (De Luca et al. 1995). They found that R-(-) isomers were more potent in sodium current blockade and they highlighted the probable usefulness of low doses of R-() mexiletine in the therapy of the abnormal hyperexcitability of the myotonic muscles, with an expectable reduction of unwanted side effects. However, the detailed cardiac electrophysiological effects of the R-(-) and S-(+) mexiletine isomers on cardiac ventricular preparations have not been investigated yet. We examined whether a significant difference exists between the cardiac electrophysiological effects of the two enantiomers. Our research group analysed the effects of the enantiomers on action potential parameters in different protocols performed on rabbit right ventricular papillary muscle preparations. The main findings of our study are that the R-(-) mexiletine displays slower offset kinetics than S-(+) mexiletine, and R-(-) mexiletine displays a tendency to more potent inhibitory effect than S$(+)$ mexiletine on Vmax, especially at early premature action potentials, i.e.: this enantiomer might exert stronger antiarrhythmic effect especially in terminating early ventricular extrasystoles. 


\section{Materials and methods}

\subsection{Conventional microelectrode technique}

All experiments were carried out in compliance with the Guide for the Care and Use of Laboratory Animals (revised in USA NIH Publication No. 85-23, revised 1996). The protocols were approved by the Review Board of the Committee on Animal Research of the University of Szeged (54/1999 OEj). Young male New Zealand rabbits (1000-2000 g) were euthanized by a blow on the neck and the hearts were removed. Free right ventricular wall and the right papillary muscles were prepared and placed into the tissue bath $(50 \mathrm{ml})$ and allowed to equilibrate for at least one hour while superfused (flow rate $4-5 \mathrm{ml} / \mathrm{min}$ ) with Locke's solution containing (in $\mathrm{mM}$ ): $\mathrm{NaCl} 120, \mathrm{KCl} 4, \mathrm{CaCl}_{2} 2, \mathrm{MgCl}_{2} 1, \mathrm{NaHCO}_{3} 22$ and glucose 11. The $\mathrm{pH}$ of this solution was 7.40 to 7.45 when gassed with $95 \% \mathrm{O}_{2}$ and $5 \% \mathrm{CO}_{2}$ at $37{ }^{\circ} \mathrm{C}$. During the equilibration period, the ventricular muscle tissues were stimulated at a basic cycle length of $1000 \mathrm{~ms}$. Electrical pulses of $2 \mathrm{~ms}$ in duration and twice diastolic threshold in intensity (S1) were delivered to the preparations through bipolar platinum electrodes. Transmembrane potentials were recorded with the use of glass capillary microelectrodes filled with $3 \mathrm{M} \mathrm{KCl}$ (tip resistance: 5 to $15 \mathrm{M} \Omega$ ). The microelectrodes were coupled through an $\mathrm{Ag}-$ $\mathrm{AgCl}$ junction to the input of a high impedance, capacitance-neutralizing amplifier (Experimetria 2004). Intracellular recordings were displayed on a storage oscilloscope (Hitachi V-555) and led to a computer system (APES) designed for online determination of the following parameters: resting membrane potential, action potential amplitude, action potential duration at $10 \%, 25 \%, 50 \%$ and $90 \%$ repolarization and the maximum rate of rise of the action potential upstroke (Vmax). The following types of stimulation were applied in the course of the experiments: stimulation with a constant cycle length of $1000 \mathrm{~ms}$ (ventricular muscles); stimulation with different constant cycle lengths ranging from 300 to $5000 \mathrm{~ms}$. In order to establish the recovery of Vmax, extra test action potentials were elicited by using 
single test pulses $\left(\mathrm{S}_{2}\right)$ in a preparation driven at a basic cycle length of $1000 \mathrm{~ms}\left(\mathrm{~S}_{1}\right)$. The $\mathrm{S}_{1}$ $\mathrm{S}_{2}$ interval was gradually increased from the end of refractory period. The action potential characteristics of the potentials evoked by each $\mathrm{S}_{2}$ were determined. The diastolic interval preceding the test action potential was measured from the point corresponding to $90 \%$ repolarization of the preceding basic action potential to delivery of $\mathrm{S}_{2}$. The effective refractory period (ERP) of the preparation, defined as the shortest S1-S2 interval that evoked a propagated action potential using a stimulus amplitude equal to twice the diastolic threshold intensity, was also determined. Once control measurements had been obtained, the preparation was superfused either for 45 min with $20 \mu \mathrm{M}$ R-(-) mexiletine or S-(+) mexiletine. The therapeutically and experimentally relevant concentration of mexiletine amounts to about $20 \mu \mathrm{M}$ (Paalman et al. 1977). Same concentration was applied at both stereoisomers. Following these periods of exposure, all action potential parameters were again obtained.

\subsection{Statistical analysis}

Statistical differences were evaluated with Student's $t$-test and differences were considered significant when $p<0.05$. Data are expressed as mean \pm S.E.M. (standard error of the mean). 


\section{Results}

Effects of mexiletine enantiomers on transmembrane action potentials

The effects of $20 \mu \mathrm{M}$ R-(-) and S-(+) enantiomers of mexiletine on action potential characteristics in rabbit ventricular/papillary muscle preparations are summarized in Table 1, with examples illustrated in Figure 1. At a stimulation cycle length of $1000 \mathrm{~ms}$ the enantiomers did not change ventricular repolarization (Table 1 and Figure 1). Neither R-(-) nor S-(+) mexiletine had effects on the action potential amplitude, the maximal diastolic potential/membrane resting potential. Both R-(-) and S-(+) mexiletine significantly increased the $\mathrm{ERP} / \mathrm{APD}_{90}$ ratio (Table 1). Both enantiomers at $20 \mu \mathrm{M}$ concentration significantly depressed the Vmax (Table 1) at a stimulation cycle length of $1000 \mathrm{~ms}$. The depression of maximal rate of rise of depolarization (Vmax) evoked by the stereoisomers (Figures 2A and 2B) was strongly dependent upon stimulation frequency ("use dependent"); i.e. as pacing cycle length was decreased (basic cycle lengths $300 \mathrm{~ms}-700 \mathrm{~ms}$ ), the depression of Vmax was increased. There was no statistically significant difference between mexiletine isomers in the degree of inhibition of Vmax (Figure 2C), though R-(-) mexiletine demonstrated a somewhat more potent inhibitory effect. Impulse conduction time (CT), another sodium channel-mediated parameter, i.e.: the time between the stimulus signal and the action potential upstroke was also prolonged significantly (Figures $3 \mathrm{~A}$ and B) by the enantiomers at fast rates. The effects of mexiletine enantiomers on early premature action potentials following final repolarization of the previous basic action potential (i.e., at a diastolic interval $=70 \mathrm{~ms}$ ) are summarized in Table 2 . Both R-(-) and S-(+) mexiletine significantly depressed the Vmax (Table 2) of early premature action potentials and R-(-) mexiletine caused a more potent inhibitory action. At the stimulation cycle length of $1000 \mathrm{~ms}$, mexiletine enantiomers inhibited the recovery of Vmax (Figure 4). The time constants for recovery of Vmax in the presence of $20 \mu \mathrm{M}$ mexiletine enantiomers were $\tau=376.0 \pm 77.8 \mathrm{~ms}$ for R-(-) mexiletine and 
$\tau=227.1 \pm 23.4 \mathrm{~ms}$ for S-(+) mexiletine. The R-(-) mexiletine seems to display slower offset kinetics, i.e.: dissociation from the sodium channels, and the difference was significant $(p<0.05)$ between mexiletine isomers in the degree of inhibition of recovery. The depression was predominant over the range of early extrasystoles. 


\section{Discussion}

\subsection{Possible mechanisms}

Mexiletine which is a widely used antiarrhythmic drug exists as a racemic mixture i.e. the available drug preparations contain both S-(+) and R-(-) enantiomers. It has been extensively studied and established that racemic mexiletine inhibits Vmax in different cardiac preparations with relatively fast recovery like lidocaine and as such it was classified as class IB antiarrhythmic drug (Campbell 1983; Varró et al. 1985). Although the enantiomers, like with sotalol, may have different effect, so far the cellular cardiac electrophysiological effect of the S-(+) and R-(-) enantiomers have never been studied and analysed. Therefore we have studied the cardiac electrophysiological effects of mexiletine enantiomers $(20 \mu \mathrm{M})$ on isolated rabbit ventricular preparations. In order to establish whether the R-(-) and S-(+) enantiomers had different property, we first examined the effect of the stereoisomers on Vmax, which is the maximum rising velocity of the action potential upstroke. Vmax measurements are indicative for $\mathrm{I}_{\mathrm{Na}}$ function (i.e.: cycle length dependent Vmax block in rabbit ventricular muscles is attributable to the inhibitory effect of mexiletine enantiomers on the fast $\mathrm{Na}^{+}$ current, but cannot be applied for quantitative estimation of sodium channel availability, which could be underestimated by such measurements (Sheets et al. 1998), since Vmax can be considered as a nonlinear indicator of the fast inward sodium current (Cohen et al. 1984). We have found that both the R-(-) and S-(+) enantiomers of mexiletine at $20 \mu \mathrm{M}$ produced a rate-dependent inhibition of the Vmax value (Figures 2A, 2B), but the inhibition was more pronounced in the case of the R-(-) mexiletine (Figure 2C). The stronger depression of Vmax by the R-(-) enantiomer can be attributed to the slower offset kinetics comparing to its $\mathrm{S}-(+)$ enantiomer. Indeed, at cycle length range of 400-1000 ms the R-(-) enantiomer caused more pronounced Vmax depression than the S-(+) one. R-(-) mexiletine suppressed Vmax of early premature action potentials significantly (Table 2), and this inhibition was also more 
pronounced than that of $\mathrm{S}-(+)$ mexiletine. Therefore we can speculate that application of medications containig only the R-(-) mexiletine might decrease the probability of a second conducted impulse occurring at short premature intervals and thereby reduces the possibility of developing re-entrant tachyarrhythmias. De Luca et al. demonstrated the stereoselective effects of mexiletine enantiomers (tested at 50 and $100 \mu \mathrm{M}$ ) on sodium currents and excitability of frog skeletal muscle fibers. They found that R-(-) isomers were more potent in sodium current blockade. Inhibition of sodium current has been found to be more pronounced when the resting membrane potential is partly depolarized ( $\mathrm{Pu}$ et al. 1998) e.g. in ischaemic tissues. Therefore the stereoselective effect of mexiletine isomers on Vmax, what we have found, could be further investigated in future experiments in cardiac preparations exposed to in vitro ischemia protocols, mimicking ischemic heart diseases. We also measured another important parameter reflecting the availability of sodium channels, next to Vmax, the impulse conduction time (CT). Before administration of each enantiomer, impulse conduction time was independent of the stimulation cycle length (300-5000 msec, Figure 3). Both enantiomers were capable of exerting marked rate-dependent impulse conduction time (CT) changes (Figure 3). The time constant for recovery of Vmax in the case of R-(-) mexiletine displays slower offset kinetics than the S-(+) mexiletine (Figure 4). The mexiletine stereoisomers did not affect repolarization (Figure 1) at basic cycle length of $1000 \mathrm{~ms}$ as shown earlier (Vaughan Williams 1998).

\subsection{Clinical implications}

A retrospective study (Gao D. et al. 2013) performed on patients with an implantable cardioverter defibrillator (ICD) revealed that when mexiletine was added to amiodarone in case of amiodarone ineffectiveness, the combination of these drugs reduced ventricular tachycardia/fibrillation events which might mean appropriate therapy in these patients. In an 
other retrospective study it has recently been demonstrated (Mazzanti et al. 2016) that longterm treatment with mexiletine shortened the QT interval and resulted in a major reduction of life-threatening arrhythmic events in LQT3 patients. Another recent study (Badri et al. 2015) concluded that in patients with acquired LQT and torsades de pointes refractory to conventional treatments, the application of mexiletine may be considered. Giving possible cellular cardiac electrophysiological explanations for the latter observations we should note that many years ago mexiletine was found to be able to abbreviate the APD of the M cells and to suppress the development of EADs (Sicouri et al. 1997) and was also found to be highly effective in decreasing dispersion of repolarization and preventing torsade des pointes in LQT2 and LQT3 models (Shimizu and Antzelevitch 1997). Turgeon et al. (1991) demonstrated in their study that R-(-) mexiletine was more efficient in the prevention of ventricular tachycardia after coronary ligation in dogs than the S- $(+)$ stereoisomer. Their work raised the possibilty that R-(-) mexiletine may possess stronger antiarrhythmic characteristics than the opposite enantiomer (Turgeon et al. 1991). On the basis of De Luca's (greater potency of R-(-) mexiletine to inhibit $\mathrm{I}_{\mathrm{Na}}$ ) and Turgeon's and our findings it might be worth examining the effects of the mexiletine stereoisomers, but especially those of the R-(-) mexiletine in different patient groups i.e.: patients with an implantable cardioverter defibrillator and receiving amiodarone or in LQT3 patients. It has emerged from experiments performed on Purkinje fibers (Varro and Lathrop 1990), that combined application of sotalol and mexiletine may produce beneficial electrophysiological effects by possibly exerting intensified antiarrhythmic efficacy and less proarrhythmic complications in patients, therefore it might be of value to examine the combined effects of sotalol and R-(-) mexiletine in future experiments and clinical studies. Regarding extracardiac implications the R-(-) mexiletine could be studied in patients with myotonic dystrophy. The pharmacokinetic parameters of the enantiomers should always be considered. Kwok et al. (1995) observed a pharmacokinetic 
difference between mexiletine stereoisomers in 12 healthy human subjects. In their study (Kwok et al. 1995) it was described that after oral administration of $200 \mathrm{mg}$ racemic mexiletine: the mean serum total R-(-) mexiletine concentrations were significantly higher than those for S-(+) mexiletine during the first 6 hours following drug administration. It was found in a human study (McErlane et al. 1987) involving five healthy subjects that the serum protein binding was significantly greater for R-(-) mexiletine than its antipode and the free fraction of S-(+) mexiletine was $28.32 \pm 1.45 \%$ and that of the R-(-) enantiomer was $19.80 \pm$ 1.49\%. Another study (Igwemezie et al. 1989) involving five healthy subjects revealed that the elimination half-life of S-(+) mexiletine was $11.0+/-3.80 \mathrm{~h}$, which was significantly longer than that of the R-(-) enantiomer, 9.10 +/- 2.90 h. A study (Mehvar et al. 2002) in rats uncovered non stereoselective distribution of the isomers to most tissues with the exception of the liver, where the concentration of the S- $(+)$ stereoisomer was more than twice of that of its antipode. This study also established a 2-fold higher tissue/serum concentration ratio for S-(+) mexiletine enantiomer as compared with the ratio for the R-(-) isomer. The most frequently seen adverse effects of mexiletine are often dose related and they affect mainly the central nervous system. Tremors, nystagmus, blurred vision, dizziness, drowsiness, confusion, ataxia, paresthesia, dysarthria, insomnia, tinnitus and convulsions are the most common side effects. Gastrointestinal disturbances can also develop during mexiletine therapy (Vaughan Williams 1998). Detailed studies are still needed to establish the pharmacokinetic difference between the two stereoisomers and its possible therapeutic and toxicological significance. 


\section{Conclusion}

Our findings have particular importance as mexiletine is still an important drug with a wide range of indications (cardiac arrhythmias, myotonic dystrophy, lidocaine-responsive neonatal epilepsy etc.). Slower detachment kinetics of R-(-) mexiletine from the sodium channels than that of S-(+) mexiletine and pronounced suppression the Vmax of early extrasystoles by R-(-) mexiletine might be of therapeutic value. Using lower doses of the probably more potent R-() mexiletine in the therapy of different disease conditions (arrhythmias, abnormal hyperexcitability of the myotonic muscles, neuropathic pain, ALS), might result in the reduction of unwanted adverse effects mentioned. To establish, whether the application of R(-) mexiletine alone would result in enhanced antiarrhythmic efficacy requires further in vitro and an vivo studies.

\section{Acknowledgements}

This work was supported by grants from the National Research, Development and Innovation Office - NKFIH PD-116011, THE ÚNKP-ÚNKP-16-4 NEW NATIONAL EXCELLENCE PRogram of THE Ministry of Human CAPACITIES, the Hungarian Scientific Research Fund (OTKA NK-104331, NN-109904), and the Hungarian Academy of Sciences.

\section{List of references}

Arita, M., Goto, M., Nagamoto, Y., and Saikawa, T. 1979. Electrophysiological actions of mexiletine (Kö1173) on canine Purkinje fibres and ventricular muscle. Br. J. Pharmacol. 67(1): 143-52. doi: 10.1111/j.1476-5381.1979.tb16117.x. PMID: 497518.

Badri, M., Patel, A., Patel, C., Liu, G., Goldstein, M., Robinson, V.M., et al. 2015. Mexiletine Prevents Recurrent Torsades de Pointes in Acquired Long QT Syndrome Refractory to Conventional Measures. JACC Clin. Electrophysiol. 1(4): 315-322. doi: 10.1016/j.jacep.2015.05.008. 
Campbell, T.J. 1983. Resting and rate-dependent depression of maximum rate of depolarisation (Vmax) in guinea pig ventricular action potentials by mexiletine, disopyramide, and encainide. J. Cardiovasc. Pharmacol. 5(2): 291-6. PMID: 6188905.

Cohen, C.J., Bean, B.P., and Tsien, R.W. 1984. Maximal upstroke velocity as an index of available sodium conductance. Comparison of maximal upstroke velocity and voltage clamp measurements of sodium current in rabbit Purkinje fibers. Circ. Res. 54(6): 636-51. doi: 10.1161/01.RES.54.6.636. PMID: 6329543.

De Luca, A., Natuzzi, F., Lentini, G., Franchini, C., Tortorella, V., and Conte Camerino, D. 1995. Stereoselective effects of mexiletine enantiomers on sodium currents and excitability characteristics of adult skeletal muscle fibers. Naunyn-Schmiedeberg's Arch. Pharmacol. 352(6): 653-61. doi: 10.1007/BF00171325. PMID: 9053738.

Gao, D., Van Herendael, H., Alshengeiti, L., Dorian, P., Mangat, I., Korley, V., et al. 2013. Mexiletine as an adjunctive therapy to amiodarone reduces the frequency of ventricular tachyarrhythmia events in patients with an implantable defibrillator. J. Cardiovasc. Pharmacol. 62(2): 199-204. doi: 10.1097/FJC.0b013e31829651fe. PMID: 23609328.

Gao, Y., Xue, X., Hu, D., Liu, W., Yuan, Y., Sun, H., et al. 2013. Inhibition of late sodium current by mexiletine: a novel pharmotherapeutical approach in Timothy syndrome. Circ. Arrhythm. Electrophysiol. 6(3): 614-22. doi: 10.1161/CIRCEP.113.000092. PMID: 23580742.

Hering, S., Bodewei, R., and Wollenberger, A. 1983. Sodium current in freshly isolated and in cultured single rat myocardial cells: frequency and voltage-dependent block by mexiletine. J. Mol. Cell. Cardiol. 15(7): 431-44. doi: 10.1016/0022-2828(83)90263-8. PMID: 6620395.

Hohnloser, S., Weirich, J., and Antoni, H. 1982. Effects of mexiletine on steady-state characteristics and recovery kinetics of $\mathrm{V} \max$ and conduction velocity in guinea pig myocardium. J. Cardiovasc. Pharmacol. 4(2): 232-9. PMID: 6175806.

Igwemezie, L., Kerr, C.R., and McErlane, K.M. 1989. The pharmacokinetics of the enantiomers of mexiletine in humans. Xenobiotica, 19(6): 677-82. doi: 10.3109/00498258909042305. PMID: 2763576.

Kwok, D.W., Kerr, C.R., and McErlane, K.M. 1995. Pharmacokinetics of mexiletine enantiomers in healthy human subjects. A study of the in vivo serum protein binding, salivary 
excretion and red blood cell distribution of the enantiomers. Xenobiotica, 25(10): 1127-42. doi: 10.3109/00498259509061913. PMID: 8578769.

Logigian, E.L., Martens, W.B., Moxley, R.T., McDermott, M.P., Dilek, N., Wiegner, A.W., et al. 2010. Mexiletine is an effective antimyotonia treatment in myotonic dystrophy type 1. Neurology, 74(18): 1441-8. doi: 10.1212/WNL.0b013e3181dc1a3a. PMID: 20439846.

Mason, J.W. 1993. A comparison of seven antiarrhythmic drugs in patients with ventricular tachyarrhythmias. Electrophysiologic Study versus Electrocardiographic Monitoring Investigators. N. Engl. J. Med. 329(7): 452-8. doi: 10.1056/NEJM199308123290702. PMID: 8332150.

Mazzanti, A., Maragna, R., Faragli, A., Monteforte, N., Bloise, R., Memmi, M., et al. 2016. Gene-Specific Therapy With Mexiletine Reduces Arrhythmic Events in Patients With Long QT Syndrome Type 3. J. Am. Coll. Cardiol. 67(9): 1053-8. doi: 10.1016/j.jacc.2015.12.033. PMID: 26940925.

McErlane, K.M., Igwemezie, L., and Kerr, C.R. 1987. Stereoselective serum protein binding of mexiletine enantiomers in man. Res. Commun. Chem. Pathol. Pharmacol. 56(1): 141-4. PMID: 3589151.

Mehvar, R., Brocks, D.R., and Vakily, M. 2002. Impact of stereoselectivity on the pharmacokinetics and pharmacodynamics of antiarrhythmic drugs. Clin. Pharmacokinet. 41(8): 533-58. doi: 10.2165/00003088-200241080-00001. PMID: 12102640.

O'Connor, A.B., and Dworkin, R.H. 2009. Treatment of neuropathic pain: an overview of recent guidelines. Am. J. Med. 122(10 Suppl): S22-32. doi: 10.1016/j.amjmed.2009.04.007. PMID: 19801049.

Paalman, A.C., Roos, J.C., Siebelink, J., and Dunning, A.J. 1977. Development of a dosage scheme for simultaneous intravenous and oral administration of mexiletine. Postgrad. Med. J. 53(Suppl 1): 128-33. doi:. PMID: 876945.

Park, H.J., and Moon, D.E. 2010. Pharmacologic management of chronic pain. Korean J. Pain, 23(2): 99-108. doi: 10.3344/kjp.2010.23.2.99. PMID: 20556211. 
$\mathrm{Pu}$, J., Balser, J.R., and Boyden, P. 1998. Lidocaine action on $\mathrm{Na}^{+}$currents in ventricular myocytes from the epicardial border zone of the infarcted heart. Circ. Res. 83(4): 431-440. doi: 10.1161/01.RES.83.4.431. PMID: 9721700.

Sheets, M.F., Hanck, D.A., and Fozzard, H.A. 1998. Nonlinear relation between $\mathrm{V}_{\max }$ and $\mathrm{I}_{\mathrm{Na}}$ in canine cardiac purkinje cells. Circ. Res. 63(2): 386-398. doi: 10.1161/01.RES.63.2.386. PMID: 2456164.

Sarkozy, A., and Dorian, P. 2007. Anti-arrhythmic Drugs. In Principles of Medical Pharmacology. Edited by H. Kalant, D.M. Grant and J. Mitchell. Elsevier Canada, Toronto. pp. $430-447$.

Shimizu, W., and Antzelevitch, C. 1997. Sodium channel block with mexiletine is effective in reducing dispersion of repolarization and preventing torsade des pointes in LQT2 and LQT3 models of the long-QT syndrome. Circulation, 96(6): 2038-47. doi: 10.1161/01.CIR.96.6.2038. PMID: 9323097.

Sicouri, S., Antzelevitch, D., Heilmann, C., and Antzelevitch, C. 1997. Effects of sodium channel block with mexiletine to reverse action potential prolongation in in vitro models of the long QT syndrome. J. Cardiovasc. Electrophysiol. 8(11): 1280-90. doi: 10.1111/j.15408167.1997.tb01019.x. PMID: 9395171.

Singh, S., Klein, R., Eisenberg, B., Hughes, E., Shand, M., and Doherty, P. 1990. Long-term effect of mexiletine on left ventricular function and relation to suppression of ventricular arrhythmia. Am. J. Cardiol. 66(17): 1222-7. doi: 10.1016/0002-9149(90)91104-E. PMID: 1700592.

Statland, J.M., Bundy, B.N., Wang, Y., Rayan, D.R., Trivedi, J.R., Sansone, V.A., et al. 2012. Mexiletine for symptoms and signs of myotonia in nondystrophic myotonia: a randomized controlled trial. J.A.M.A. 308(13): 1357-65. doi: 10.1001/jama.2012.12607. PMID: 23032552.

Turgeon, J., Uprichard, A.C., Bélanger, P.M., Harron, D.W., and Grech-Bélanger, O. 1991. Resolution and electrophysiological effects of mexiletine enantiomers. J. Pharm. Pharmacol. 43(9): 630-5. doi: 10.1111/j.2042-7158.1991.tb03552.x. PMID: 1685521. 
Varró, A., and Lathrop, D.A. 1990. Sotalol and mexiletine: combination of rate-dependent electrophysiological effects. J. Cardiovasc. Pharmacol. 16(4): 557-67. doi: 10.1016/00222828(90)91356-C. PMID: 1706796.

Varró, A., Elharrar, V., and Surawicz, B. 1985. Frequency-dependent effects of several class I antiarrhythmic drugs on Vmax of action potential upstroke in canine cardiac Purkinje fibers. J. Cardiovasc. Pharmacol. 7(3): 482-92. doi:. PMID: 2410678.

Vaughan Williams, E.M. 1998. Class 1 Antiarrhytmic Action. In Control of Cardiac Rhythm. Edited by E.M. Vaughan Willams and J.C. Somberg. Lippincott-Raven Publishers, Philadelphia. pp. 11-32.

Weiss, M.D., Macklin, E.A., Simmons, Z., Knox, A.S., Greenblatt, D.J., Atassi, N., et al. 2016. A randomized trial of mexiletine in ALS: Safety and effects on muscle cramps and progression. Neurology, 86(16): 1474-81. doi: 10.1212/WNL.0000000000002507. PMID: 26911633.

Yamaguchi, I., Singh, B.N., and Mandel, W.J. 1979. Electrophysiological actions of mexiletine on isolated rabbit atria and canine ventricular muscle and purkinje fibres. Cardiovasc. Res. 13(5): 288-96. doi: 10.1093/cvr/13.5.288. PMID: 476749. 


\section{Figure legends}

Figure 1. Effect of R-(-) mexiletine (A) and S-(+) mexiletine (B) on action potential waveform of rabbit ventricular muscle at stimulation cycle length of $1000 \mathrm{~ms}$. The amplitude and time scales for the recording of the first derivative of the transmembrane voltage with respect to time (Vmax) are indicated to the right.

Figure 2. Rate-dependent effect of R-(-) mexiletine (A) and S-(+) mexiletine (B) on the maximum rate of depolarization (Vmax). Results are mean \pm S.E.M., $*=p<0.05, * *=p<$ 0.01 vs control, $n=8-8$. Comparison of the rate-dependent effects of R-(-) mexiletine and S(+) mexiletine on the maximum rate of depolarization (Vmax) (C). Values indicated on ordinate are calculated by dividing the Vmax value measured in the presence of either R-(-) or $\mathrm{S}-(+)$ mexiletine with its own control Vmax value.

Figure 3. Rate-dependent effect of R-(-) mexiletine (A) and S- $(+)$ mexiletine (B) on the conduction time (CT). Results are mean \pm S.E.M., $*=p<0.05, * *=p<0.01$ vs control, $n=8-8$. The increase in CT in the presence of $\mathrm{S}-(+)$ isomer is less than that following exposure to the R-(-) isomer.

Figure 4. Effects of R-(-) and S-(+) enantiomers of mexiletine on recovery of Vmax. Means are shown. The abscissa indicates diastolic intervals in milliseconds, and the ordinate shows the Vmax. The time constants for recovery of Vmax were $\tau=376.0 \pm 77.8 \mathrm{~ms}$ for $\mathrm{R}-(-)$ mexiletine and $\tau=227.1 \pm 23.4 \mathrm{~ms}$ for $\mathrm{S}-(+)$ mexiletine. The difference was significant $(p<0.05)$ between mexiletine isomers in the degree of inhibition of recovery. 
A. CONTROL
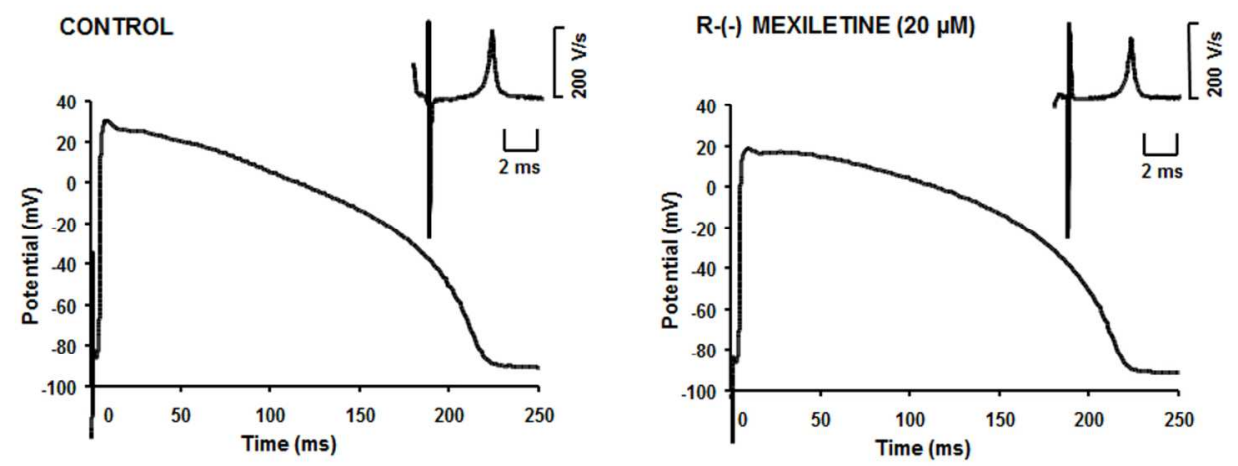

B.

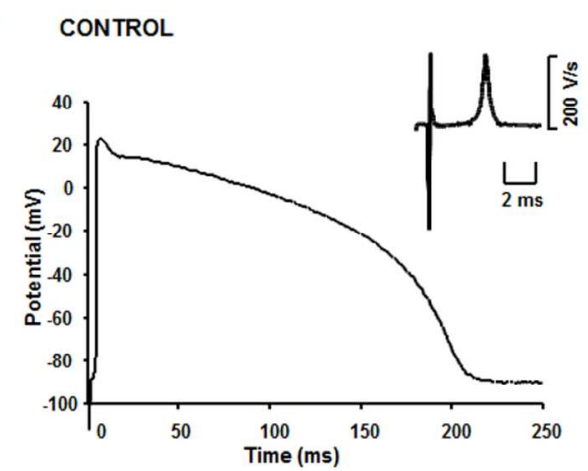

S-(+) MEXILETINE $(20 \mu M)$

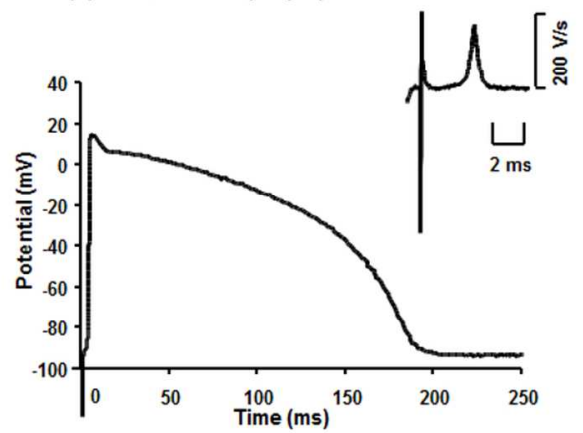

Figure 1 improved DPI February 12 $101 \times 77 \mathrm{~mm}(300 \times 300$ DPI $)$ 

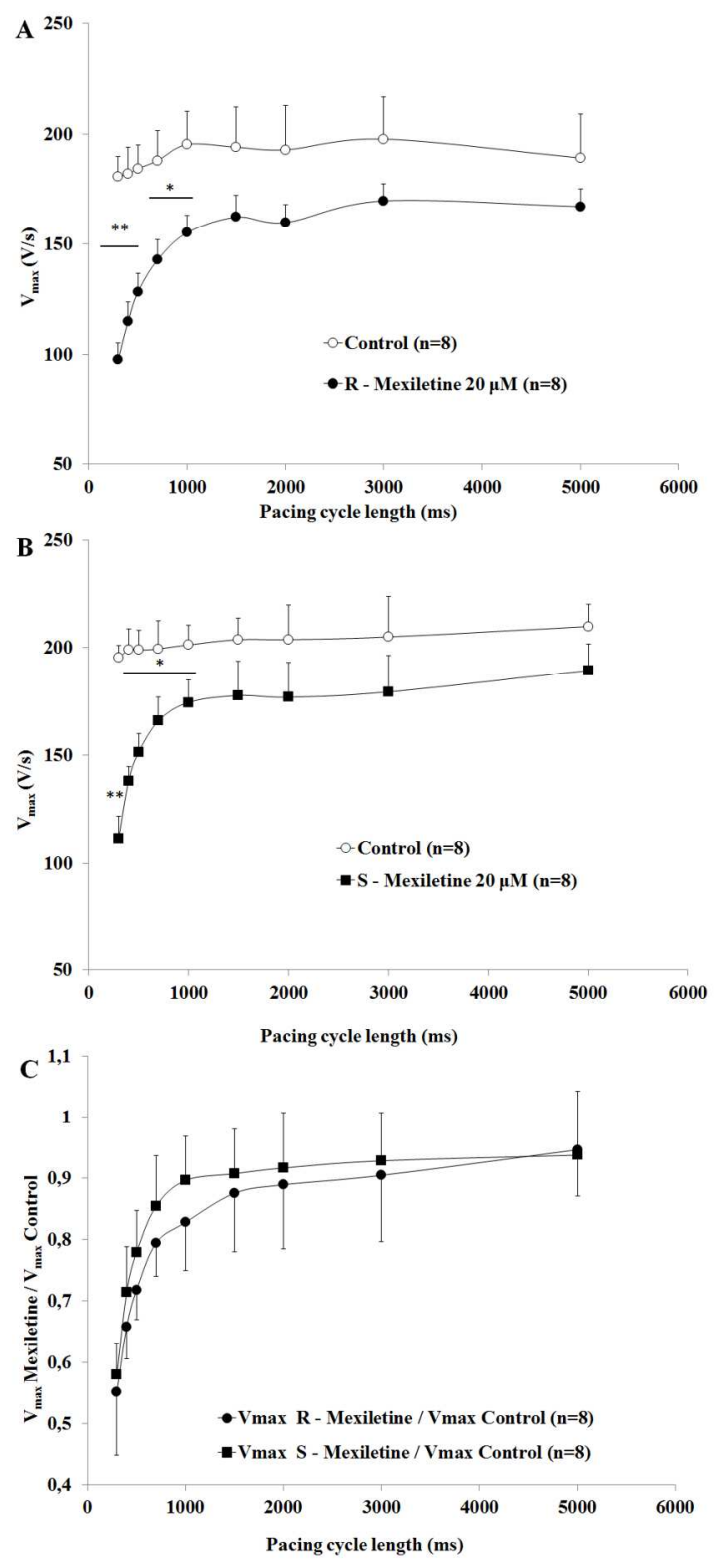

Corrected Figure 2 assemled February 12 $183 \times 401 \mathrm{~mm}(300 \times 300 \mathrm{DPI})$ 

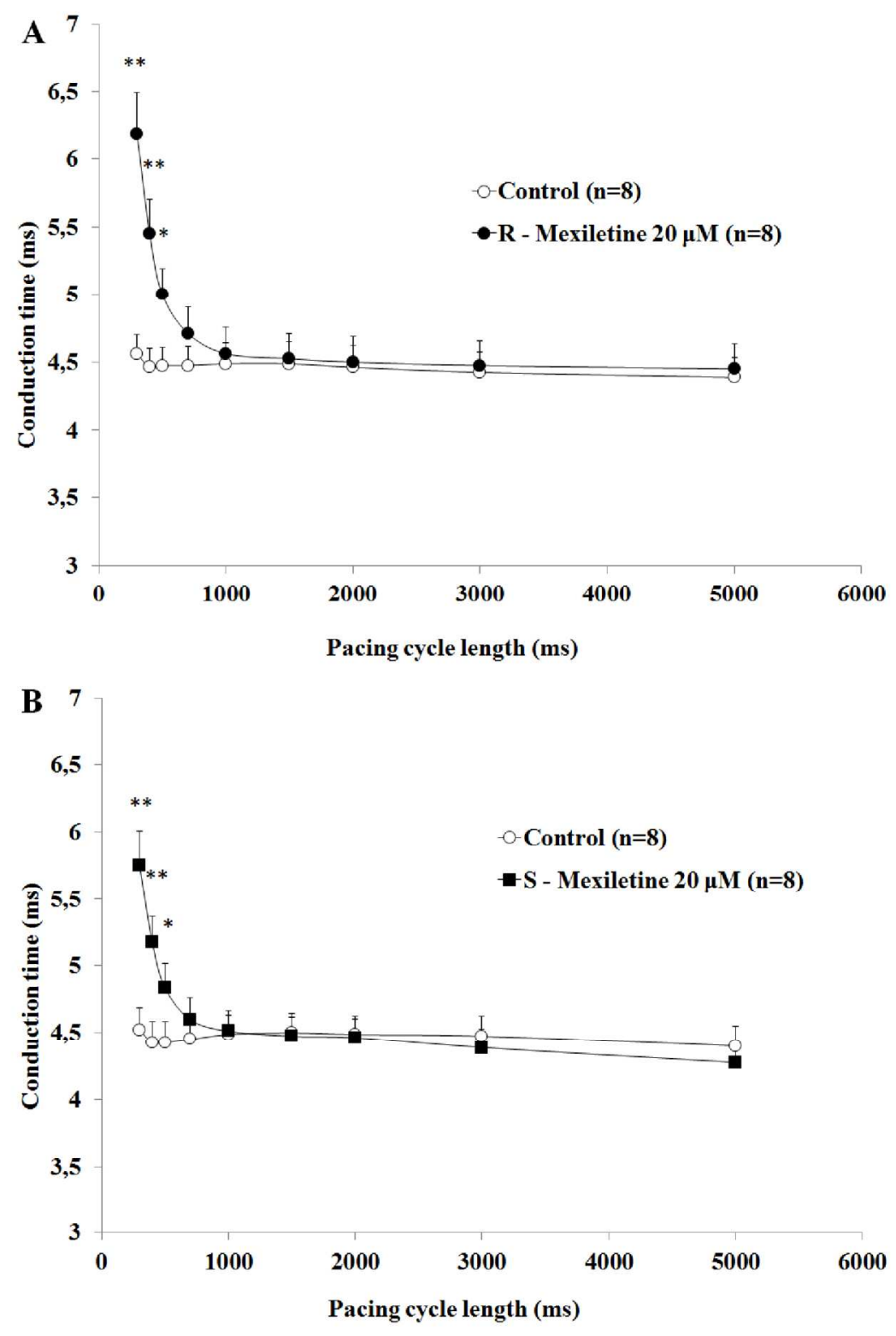

Corrected Figure 3 assembled February 12 $184 \times 275 \mathrm{~mm}(300 \times 300 \mathrm{DPI})$ 


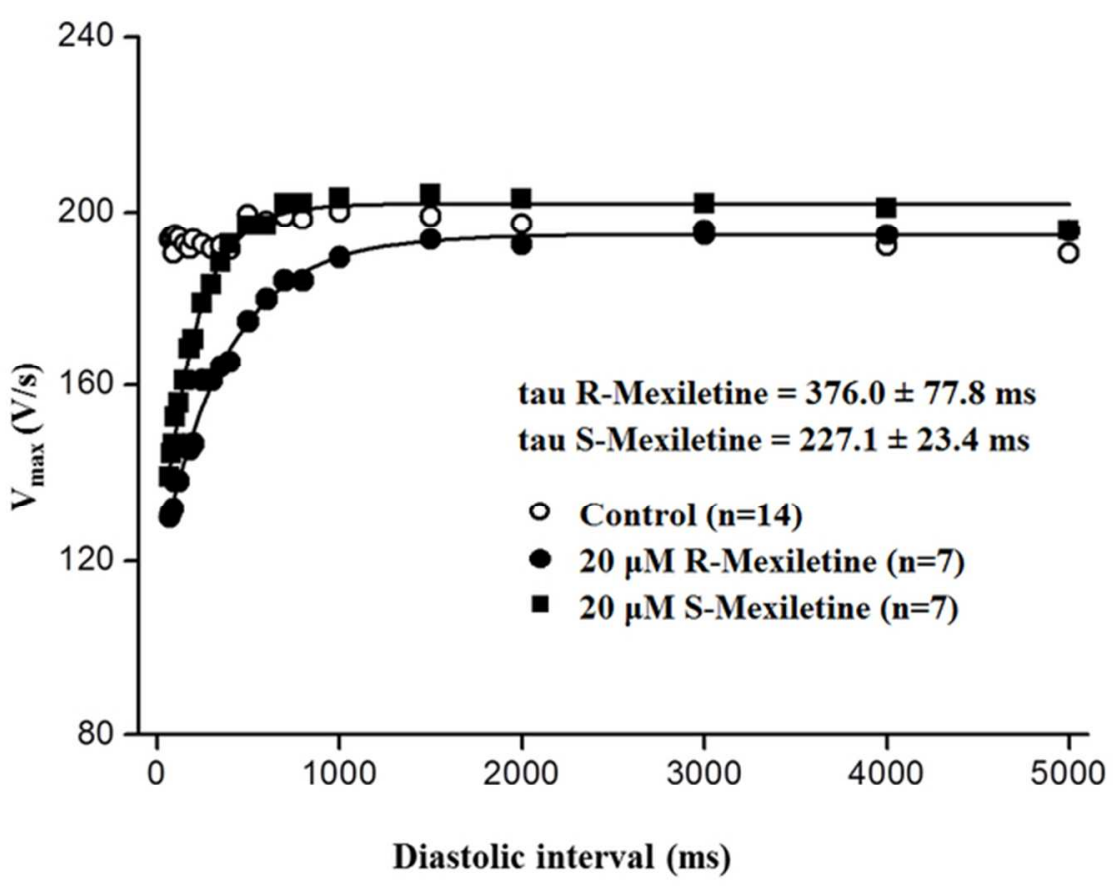

Figure 4

$62 \times 47 \mathrm{~mm}(300 \times 300 \mathrm{DPI})$ 
Table 1. The electrophysiological effects of $R-(-)$ and $S-(+)$ mexiletine enantiomers in rabbit ventricular papillary muscle at basic cycle length of $1000 \mathrm{~ms}$

Means \pm SEM. MDP, maximum diastolic potential; APA, action potential amplitude; APD 90 , action potential duration at 90\% of repolarization; $\mathrm{APD}_{50}$, action potential duration at 50\% of repolarization; Vmax, maximum rising velocity ofthe action potential upstroke; ERP, effective refractory period; $(n)$, number of observations (i.e., number of preparations obtained from different animals). ${ }^{*} p<0.05$

\begin{tabular}{|l|l|l|l|l|l|l|}
\hline PARAMETERS & MDP $(\mathbf{m V})$ & APA $(\mathbf{m V})$ & APD90 $(\mathbf{m s})$ & APD $_{\mathbf{5 0}}(\mathbf{m s})$ & Vmax (V/s) & ERP/APD \\
\hline Control & $\begin{array}{l}-85.1 \pm 1.2 \\
(8)\end{array}$ & $\begin{array}{l}108.7 \pm 1.3 \\
(8)\end{array}$ & $\begin{array}{l}192.2 \pm 8.4 \\
(8)\end{array}$ & $\begin{array}{l}156.0 \pm 8.0 \\
(8)\end{array}$ & $\begin{array}{l}200.2 \pm 13.1 \\
(8)\end{array}$ & $\begin{array}{l}0.953 \pm 0.021 \\
(6)\end{array}$ \\
\hline $\begin{array}{l}\text { R-(-)Mexiletine 20 } \\
\boldsymbol{\mu M}\end{array}$ & $-85.2 \pm 1.7$ & $\begin{array}{l}104.2 \pm 2.5 \\
(8)\end{array}$ & $\begin{array}{l}193.3 \pm 6.9 \\
(8)\end{array}$ & $\begin{array}{l}155.7 \pm 7.3 \\
(8)\end{array}$ & $\begin{array}{l}162.7 \pm 7.9^{*} \\
(8)\end{array}$ & $\begin{array}{l}1.031 \pm 0.028^{*} \\
(6)\end{array}$ \\
\hline Control & $\begin{array}{l}-83.4 \pm 1.7 \\
(8)\end{array}$ & $\begin{array}{l}105.9 \pm 1.7 \\
(8)\end{array}$ & $\begin{array}{l}184.2 \pm 11.9 \\
(8)\end{array}$ & $\begin{array}{l}148.9 \pm 13.9 \\
(8)\end{array}$ & $\begin{array}{l}205.1 \pm 12.3 \\
(8)\end{array}$ & $\begin{array}{l}0.942 \pm 0.021 \\
(6)\end{array}$ \\
\hline $\begin{array}{l}\boldsymbol{S} \text {-(+) Mexiletine 20 } \\
\boldsymbol{\mu M}\end{array}$ & $\begin{array}{l}-83.9 \pm 1.1 \\
(8)\end{array}$ & $\begin{array}{l}106.9 \pm 1.8 \\
(8)\end{array}$ & $\begin{array}{l}198.7 \pm 13.1 \\
(8)\end{array}$ & $\begin{array}{l}161.3 \pm 12.4 \\
(8)\end{array}$ & $\begin{array}{l}167.2 \pm 10.5^{*} \\
(8)\end{array}$ & $\begin{array}{l}0.997 \pm 0.015^{*} \\
(6)\end{array}$ \\
\hline
\end{tabular}


Table 2. The electrophysiological effects of $R-(-)$ and $S-(+)$ mexiletine enantiomers on the premature action potentialat 70 ms of diastolic interval in rabbit ventricular papillary muscle.

Means \pm SEM. MDP, maximum diastolic potential; APA, action potential amplitude; APD $_{90}$, action potential duration at $90 \%$ of repolarization; $\mathrm{APD}_{90}$, action potential duration at 90\% ofrepolarization; Vmax, maximum rising velocity ofthe action potential upstroke; ERP, effective refractory period; $(n)$, number of observations (i.e., number of preparations obtained from different animals). ${ }^{*} p<0.05$

\begin{tabular}{|c|c|c|c|c|c|}
\hline PARAMETERS & MDP (mV) & APA $(m V)$ & $\mathrm{APD}_{90}(\mathrm{~ms})$ & $\mathrm{APD}_{50}(\mathrm{~ms})$ & $\operatorname{Vmax}(\mathrm{V} / \mathrm{s})$ \\
\hline Control & $\begin{array}{l}-83.4 \pm 1.5 \\
(7)\end{array}$ & $\begin{array}{l}109.6 \pm 2.1 \\
(7)\end{array}$ & $\begin{array}{l}204.4 \pm 14.5 \\
\text { (7) }\end{array}$ & $\begin{array}{l}165.9 \pm 15.7 \\
(7)\end{array}$ & $\begin{array}{l}208.2 \pm 30.2 \\
(7)\end{array}$ \\
\hline $\begin{array}{l}\mathrm{R}-(-) \text { Mexiletine } 20 \\
\boldsymbol{\mu M}\end{array}$ & $\begin{array}{l}-86.0 \pm 0.9 \\
(7)\end{array}$ & $\begin{array}{l}107.9 \pm 2.1 \\
(7)\end{array}$ & $\begin{array}{l}202.5 \pm 9.5 \\
(7)\end{array}$ & $\begin{array}{l}161.5 \pm 11.6 \\
(7)\end{array}$ & $\begin{array}{l}129.7 \pm 29.9 * \\
(7)\end{array}$ \\
\hline Control & $\begin{array}{l}-85.0 \pm 1.8 \\
(7)\end{array}$ & $\begin{array}{l}111.3 \pm 2.6 \\
(7)\end{array}$ & $\begin{array}{l}200.7 \pm 13.4 \\
\text { (7) }\end{array}$ & $\begin{array}{l}164.2 \pm 13.9 \\
(7)\end{array}$ & $\begin{array}{l}185.6 \pm 18.4 \\
(7)\end{array}$ \\
\hline $\begin{array}{l}\text { S -(+) Mexiletine } 20 \\
\mu \mathrm{M}\end{array}$ & $\begin{array}{l}-87.4 \pm 1.2 \\
(7)\end{array}$ & $\begin{array}{l}110.0 \pm 2.5 \\
(7)\end{array}$ & $\begin{array}{l}198.9 \pm 18.5 \\
(7)\end{array}$ & $\begin{array}{l}162.0 \pm 14.6 \\
(7)\end{array}$ & $\begin{array}{l}142.3 \pm 13.6^{*} \\
(7)\end{array}$ \\
\hline
\end{tabular}

